\title{
PARTICIPACIÓN DE COMUNIDADES EN EL MUSEO NACIONAL DE COLOMBIA DESDE UN ANÁLISIS HISTÓRICO NORMATIVO
}

\author{
COMMUNITY PARTICIPATION IN THE NATIONAL MUSEUM OF COLOMBIA \\ FROM A HISTORICAL-LEGAL ANALYSIS
}

Jhonny Antonio Pabón Cadavid

\begin{abstract}
Los museos nacionales son espacios privilegiados para la creación de identidades políticas y culturales en el marco del Estadonación. El presente artículo analiza la forma en que las constituciones y el derecho del patrimonio cultural afectan las prácticas de los museos nacionales con relación a la participación de múltiples comunidades patrimoniales. Tomando como ejemplo el desarrollo histórico normativo del Museo Nacional de Colombia, se analiza cómo desde su fundación las funciones, operaciones y representaciones de la nación han sido moldeadas por las normas legales. El artículo propone entender el papel de las comunidades bajo cuatro diferentes perspectivas: (1) comunidades como exhibición, (2) como consultores, (3) como participantes y (4) como administradores. Para que las comunidades sean administradores se requieren marcos legales que promuevan políticas dentro del museo que garanticen la diversidad cultural y los derechos humanos de las comunidades indígenas y afrocolombianas.
\end{abstract}

Palabras claves: Museos Nacionales, legislación patrimonial, patrimonio cultural, Colombia, derechos humanos.

National museums are privileged spaces to construct political and cultural identities within the framework of a nation-state. The aim of this article is to analyze how political constitutions and cultural heritage law influence national museums' practices in relation to the participation of multiple heritage communities. Using the National Museum of Colombia as a reference of historical development, this article analyzes how legal regulations have shaped its functions, operations, and representations since its foundation. It also presents proposals to understand the role of communities from four different perspectives: (1) as exhibitions, (2) as consultants, (3) as participants, and (4) as managers. To enable the fourth perspective, legal frameworks promoting policies that guarantee the cultural diversity and human rights of indigenous and Afro-Colombian communities are necessary.

Key words: National Museums, heritage law, cultural heritage, Colombia, human rights.

El derecho del patrimonio cultural define qué recursos culturales están protegidos, preservados y legados a las generaciones venideras. La legislación patrimonial es desde esta perspectiva una herramienta de las generaciones presentes para contribuir a diseñar el futuro. Los museos nacionales son espacios privilegiados de participación cultural y política en la representación de cómo una sociedad narra su pasado, interpreta su presente e imagina su porvenir. Estas instituciones nacionales de la memoria están creadas y reguladas por el derecho del patrimonio cultural. Tradicionalmente, las representaciones en los museos nacionales han sido gestionadas y dominadas por discursos que sirven a las élites del país, las mismas que han estado a cargo de construir el Estado-nación.

Benedict Anderson definió las naciones como comunidades limitadas, soberanas e imaginadas.
Limitadas porque se basan en territorios específicos, soberanas porque se conciben dentro de un Estado moderno e imaginadas ya que sus miembros no se conocen entre sí (Anderson 2006). Asimismo, Anderson destacó que el museo es un instrumento importante para la construcción de la nación (Anderson 2006:178). Por otro lado, tenemos el concepto de comunidad patrimonial, que se refiere a un grupo de personas que, en el marco de la acción pública, valoran ciertos recursos culturales que desean mantener y transmitir a generaciones futuras (FARO Convention, artículo 2b). Las comunidades patrimoniales no coinciden necesariamente con los límites y la construcción del Estado-nación, de manera que dentro de un país existen múltiples comunidades patrimoniales, por ejemplo, diferentes comunidades indígenas o diversos grupos que comparten una misma lengua, religión o identidad racial.

\footnotetext{
${ }^{1}$ Victoria University of Wellington, Nueva Zelanda. pabonjhon@myvuw.ac.nz

Recibido: junio 2019. Aceptado: junio 2020.

http://dx.doi.org/10.4067/S0717-73562021005000501. Publicado en línea: 4-junio-2021.
} 
Este artículo parte de la siguiente cuestión: ¿cómo el sistema normativo, especialmente los marcos constitucionales y el derecho del patrimonio cultural, afectan las prácticas de los museos nacionales? Además, ¿cómo estos marcos promueven la participación de múltiples comunidades del patrimonio en la operación del museo? Por lo tanto, para el desarrollo del presente trabajo, propongo entender la participación de diferentes comunidades patrimoniales en la práctica de los museos nacionales utilizando cuatro roles o escenarios diferentes: (1) las comunidades como exhibición, (2) las comunidades como consultores, (3) las comunidades como participantes y (4) las comunidades como administradores o gestores. Estos roles se dan en cada función del museo, como en la selección, la formación de colecciones, la conservación y las exhibiciones. En el primer escenario, por exhibición nos referimos a la situación en la que las identidades, narraciones y artefactos de las comunidades son objetos de una narrativa impuesta por el museo o cuando la existencia misma de las comunidades es excluida completamente. En el segundo escenario, el museo consulta a las comunidades acerca de las interpretaciones de sus tradiciones y los usos de sus artefactos. En el tercer escenario, las comunidades son participantes donde se involucran activamente en la selección, colección, interpretaciones y la creación de guiones y exposiciones. Las comunidades son los administradores cuando tienen poder de decisión o un nivel equilibrado de negociación en la toma de decisiones de todas las políticas y procesos. Estos roles están enmarcados por la Constitución política del país, las leyes de patrimonio cultural, prácticas de los museos, además de las realidades y mentalidades sociopolíticas, teniendo en cuenta que una de las funciones de las políticas culturales es delinear el nivel de participación de diversas comunidades en la asignación de recursos oficiales para la gestión del patrimonio cultural.

Estas categorías no son excluyentes, de tal manera que un museo puede operar en donde las comunidades tienen de forma simultánea diferentes roles. Así, por ejemplo, el Museo Nacional de Australia, en sus políticas para el respeto de los derechos culturales de las comunidades indígenas, adopta la consulta, el consentimiento informado y la participación de las comunidades indígenas como principios para sus exhibiciones (National Museum of Australia 2015). Sin embargo, la legislación de Australia de 2013 para la protección de objetos culturales en préstamo impide que se inicien acciones legales de repatriación cuando los museos en Australia realicen exhibiciones con material que se encuentre en préstamo por instituciones foráneas (Protection of Cultural Objects on Loan Act 2013). Esta inmunidad afecta principalmente el patrimonio cultural de las comunidades indígenas australianas. De hecho, la historia legislativa muestra que esta norma es una respuesta, ante el intento de la comunidad Dja Dja Wurrung, en el año 2006, por recuperar sus objetos culturales que estaban exhibidos en Australia por préstamo del Museo británico (Forrest 2014). La legislación del 2013 busca brindar seguridad jurídica a posteriores exhibiciones, especialmente del Museo Nacional de Australia, con colecciones y objetos en préstamo, como la polémica exhibición del 2015 titulada Encuentros (Le Breton Poll 2017). En este contexto se observa que la legislación australiana, en relación con exhibiciones de objetos que se encuentran en colecciones foráneas, propicia un enfoque de comunidades como exhibición y restringe una orientación hacia las comunidades como participantes y administradores, protegiendo, en la práctica, particularmente colecciones de los museos británicos creadas durante la época Colonial.

De acuerdo con lo anterior, en la primera parte de este trabajo señalaremos la función de los museos nacionales, y luego se analizará el papel de la legislación de patrimonio cultural, resaltando la reciente noción de derecho humano al patrimonio cultural. Articulando estos puntos, la tercera sección analizará en el contexto específico de Colombia el desarrollo jurídico político alrededor del Museo Nacional. La metodología en esta sección consiste en estudiar la evolución histórica de las normas relacionadas con el Museo Nacional de Colombia dentro de los diferentes marcos constitucionales en los que se han creado estas leyes; desde allí, queremos analizar, constatar y contrastar esos marcos normativos con la participación de las comunidades en las prácticas y gestión del museo. Finalmente, se presentan las conclusiones.

\section{Museos Nacionales}

Los museos, al igual que otras instituciones de la memoria, deciden qué merece ser coleccionado, conservado y representado como parte de la memoria colectiva, desempeñando un papel clave en la anticipación de los recursos culturales que se transmitirán a las próximas generaciones y en las interpretaciones del pasado. El poder simbólico de los museos nacionales -junto con sus actividades específicas de coleccionar, exhibir y preservar- hace de estas instituciones espacios patrimoniales ideales para construir el Estado nación, formar identidades culturales, diseminar modelos de ciudadanía y diseñar comunidades imaginadas.

Los museos nacionales son parte de la narrativa y representación oficial de lo que una identidad nacional proyecta ser. Como señala Peter Aronsson, los museos nacionales: "[ $[. .$.$] actúan como el lugar más prestigioso$ para legitimar los valores de la naturaleza, la cultura, el arte y la historia... y presentan un conocimiento culturalmente formateado para legitimar el orden y 
la dirección de la sociedad, la nación y el Estado" (Aronsson 2015:174).

Los museos nacionales escriben y exhiben una versión de la historia del país, encarnan narrativas que se ajustan a una visión particular del pasado y del presente de la nación (Mozaffari 2007). Ellos animan a la población a sentirse miembros de una comunidad imaginada, diseñando parte de su futura identidad política y cultural. La autoridad de los museos nacionales es un medio para la promulgación de concepciones oficiales de cómo debe ser la comunidad imaginada $\mathrm{y}$ un productor de subjetividades que, a través de las representaciones, contribuye a las exclusiones sociales y refuerza las relaciones de poder dentro de la sociedad.

Desde sus orígenes, los museos han tenido un propósito educativo y son parte de la arquitectura educativa del Estado (Wittlin 1949). En el siglo XVIII y XIX, los museos públicos crecieron como instrumentos didácticos al servicio de la construcción de la nación. Por ejemplo, en el plano artístico, como lo demuestra Dominique Poulot, el museo tuvo como objetivo el fomento de corrientes de arte específicas esenciales para crear y expresar la identidad y el orgullo de la nación (Poulot 2015:106). Además de esos contextos locales del Estado-nación, los museos fueron también el resultado de proyectos transnacionales de flujos de conocimiento científico. Las estrategias pedagógicas fueron compartidas internacionalmente durante la formación y desarrollo de los museos, con el objetivo de lograr una educación cívica creando públicos nacionales (Berger 2015:29). Los museos nacionales solían estar ubicados bajo la administración del Ministerio de Educación y eran una parte importante de las políticas educativas dirigidas por el Estado (Elgenius 2015:149).

Los museos nacionales invitan a la gente a conceptualizar un sentido de identidad nacional y diferencia racional hacia otras comunidades, tomando una posición crucial en la construcción del patrimonio nacional. Hasta hace poco los museos nacionales han operado predominantemente como instituciones elitistas $\mathrm{y}$ autoritarias en las que las voces de las comunidades han estado casi ausentes, así las decisiones sobre qué coleccionar, exhibir y qué guiones elaborar descansaban en un pequeño grupo de profesionales de museos, coleccionistas y expertos (Karp 1992:9). En este sentido, el museo nacional solamente representaba la voz del grupo dominante.

Las políticas multiculturales han fomentado en los museos nacionales un replanteamiento de sus fundamentos, funcionamiento y organización. Las políticas del reconocimiento que surgieron en la segunda mitad del siglo XX han traído una ruptura en el monopolio de los discursos del Estado-nación (Taylor 1994). El reconocimiento de la multiculturalidad inserta nuevas voces en la construcción de las identidades nacionales. Además, la crítica institucional de los años setenta colocó en entredicho el papel de los museos en la legitimación del Estado-nación a través de la construcción de una historia, un patrimonio y un canon establecidos autoritariamente (Steyerl 2009:15). Ese enfoque crítico preguntó cuáles voces eran incorporadas en la narración del museo y a quién las políticas culturales oficiales apuntaban representar e interpretar.

Losmuseosnacionalesendiferentes partes delmundo están revisando su rol y desarrollando un nuevo enfoque al patrimonio. En particular, los museos de algunos países en contextos poscoloniales y en posconflicto se están convirtiendo en un lugar de reinvención debido a la necesidad de articular las identidades de múltiples grupos históricamente excluidos y ayudar a reconstruir comunidades, reconociendo los errores del pasado. En contextos de sociedades de transición, como Sudáfrica, los museos han sido llamados por el gobierno como agentes para la reconciliación y la construcción de la nación (Witz 2006:107). Además, los marcos legales que regulan las instituciones de patrimonio y memoria están evolucionando, reflejando y configurando los cambios en relación con una mayor participación democrática. Por ejemplo, en el contexto neozelandés, la legislación del museo nacional (Te Papa Tongarewa) incluye en la estructura organizacional mecanismos para que las comunidades maoríes sean parte en la toma de decisiones y administración del museo. Esto va de la mano con una realidad sociopolítica donde los derechos de las comunidades indígenas son parte de la constitución material efectiva del país. En este contexto, la negociación y la participación de diversas comunidades en la gestión del museo nacional crea representaciones que conllevan a la coexistencia en la esfera pública de diversas poblaciones con diferentes patrimonios culturales y lingüísticos.

\section{Ley de Patrimonio Cultural e Identidad}

La Ley de Patrimonio Cultural es la infraestructura normativa y legal que da forma a las operaciones y discursos de las instituciones nacionales de la memoria, tales como los museos o bibliotecas nacionales que son creadas por la legislación del patrimonio cultural. A través de la ley del patrimonio cultural, el Estado decide asignar los recursos normativos, institucionales y económicos para crear, preservar, proteger y difundir los recursos culturales, especialmente de aquellos que están alineados con las narrativas oficiales de una identidad nacional. Los recursos burocráticos, políticos y económicos asignados por la legislación del patrimonio son comúnmente utilizados por las élites políticas y culturales interesadas en la construcción de nación. Esta intensa intervención legal en aspectos culturales tiene sus orígenes en el surgimiento de las repúblicas democráticas liberales. 
La transición radical en 1789 del antiguo régimen monárquico francés a un modelo republicano liberal de Estado-nación estableció la base de la idea política moderna del patrimonio y las instituciones nacionales de la memoria, como bibliotecas, archivos y museos. Los archivos nacionales fueron creados en 1790, el Museo Central de las Artes de la República (después llamado museo del Louvre) en 1793, y la Bibliothèque Nationale en 1795 (Favier 2004; Oliver 2007). La revolución produjo la destrucción de palacios, iglesias, bibliotecas, monumentos, estatuas, pinturas, libros y otras instituciones culturales y recursos que representaban el poder de la monarquía (Shiner 2003:169). En 1794, el abate Grégoire informó estos actos de vandalismo en la convención nacional y propuso que el Estado asumiera la responsabilidad de crear una política cultural para la protección del patrimonio del Estado-nación (Sax 1990). Así se creó la idea moderna de un patrimonio nacional en el marco de la república y como parte de las políticas de identidad francesas. En este contexto, las políticas de patrimonio se basaron en ideologías monoculturales y se utilizaron para crear una comunidad imaginada homogénea.

Hoy en día las constituciones políticas contemporáneas definen en gran parte los marcos legales de las instituciones nacionales del patrimonio cultural. De esta forma, la constitución orienta y establece mandatos para que las políticas del Estado sean monoculturales o multiculturales. Por ejemplo, la Constitución Política de Colombia declara que la cultura, en sus diversas manifestaciones, es la base de la nacionalidad e impone al Estado la obligación de promover la difusión de los valores culturales de la nación (Constitución Política de Colombia 1991, artículo 70). Sin embargo, en este caso, el multiculturalismo se centra en una identidad nacional única para el país (que podría integrar manifestaciones culturales de diversas comunidades). Nuevos enfoques constitucionales reconocen y promueven la existencia de múltiples comunidades nacionales dentro de un Estado, como los estados plurinacionales de las constituciones de Bolivia (2009) y Ecuador (2008) o el modelo bicultural de Nueva Zelanda.

Estas constituciones reafirman el compromiso del Estado con los derechos culturales, sin embargo, las instituciones de la memoria, y en particular los museos, han sido deficientes en reconocer estos derechos y han operado sin tener en cuenta un marco de derechos humanos. Tan solo recientemente se ha empezado a discutir con mayor vigor la relación entre derechos humanos y museos, especialmente alrededor de la repatriación de restos humanos y objetos que se encuentran en museos europeos (ICOM 2018). En este contexto del derecho humano, el patrimonio cultural cobra especial relevancia.

\section{El derecho al patrimonio como derecho humano}

El patrimonio cultural, como parte de los derechos humanos está unido al reconocimiento muy reciente y en evolución de los derechos culturales. La Convención Marco Europea sobre el Valor del Patrimonio Cultural para la Sociedad (Convención FARO 2005) establece que "los derechos relacionados con el patrimonio cultural son inherentes al derecho a participar en la vida cultural, tal como se define en la Declaración Universal de los Derechos Humanos" (2005, artículo 1). La Convención FARO promueve la participación de las comunidades en la gestión del patrimonio como parte del afianzamiento de la democracia participativa. Además, el informe de la experta independiente en el campo de los derechos culturales para la Alta Comisión de Derechos Humanos de las Naciones Unidas (ACNUDH), presentado al Consejo de Derechos Humanos en 2011, discutió el derecho de acceso y disfrute del patrimonio cultural como parte del derecho internacional de los derechos humanos (Shaheed 2011). Allí se muestra que el derecho al patrimonio cultural abarca el derecho de las comunidades a gestionar su patrimonio cultural. Farida Shaheed destaca que el derecho al patrimonio "incluye el derecho a participar en la identificación, interpretación y desarrollo del patrimonio cultural, así como al diseño e implementación de políticas y programas de preservación/salvaguardia" (Shaheed 2011: 20). Desde esta perspectiva las comunidades tienen el derecho a participar en la designación y administración de su patrimonio.

El derecho al patrimonio está conectado a otros derechos humanos tales como el derecho a participar en la vida cultural, la libertad de expresión, la libertad de creencias y religión, el derecho a la información, el derecho a la educación y los derechos de las minorías. En sí mismo, el derecho al patrimonio es a la vez un derecho individual y un derecho colectivo. Como un derecho colectivo se expresa por ejemplo en el derecho de los pueblos indígenas a la libre determinación y al mantenimiento, control, protección y desarrollo de su patrimonio cultural (Shaheed 2011:20). Este atributo del derecho al patrimonio también se encuentra en el Convenio 169 de la OIT sobre pueblos indígenas y tribales en países independientes (1989:169). Este Convenio es el instrumento internacional vinculante más importante para el reconocimiento de los derechos indígenas, el cual abarca, entre otras cosas, la protección de los modos de vida, sus derechos intelectuales y sus derechos del patrimonio cultural.

Teniendo en cuenta estos marcos legales, a continuación analizaré el origen y desarrollo histórico del Museo Nacional de Colombia, ya que es un ejemplo de cómo las disposiciones constitucionales y la ley orientan la identidad y el enfoque de la gestión del patrimonio, al establecer políticas monoculturales o 
políticas multiculturales. Además, se identifican los escenarios presentados en la introducción (comunidades como exhibición, como consultores, como participantes y administradores) que se enmarcan en este desarrollo histórico y que incluyen los desafíos de construir un Museo Nacional de la Memoria en el contexto de un proceso de justicia transicional. En este análisis, el enfoque estará en la interacción del museo con las comunidades indígenas y las comunidades afrocolombianas, ya que son dos grupos específicos que han sido históricamente oprimidos y marginados en Colombia.

\section{Museo Nacional de Colombia}

Las repúblicas latinoamericanas creadas durante el siglo XIX fueron un laboratorio de las élites criollas en la construcción de Estados-nación. Las instituciones y los experimentos republicanos se basaron en ideas liberales influenciadas por la Revolución Francesa. Los gobiernos de estos países diseñaron proyectos nacionales basados en la estandarización étnica, religiosa y lingüística; promovieron una sociedad basada en el mestizaje racial que compartía la religión católica y el idioma español (Martínez-Echazábal 1998). Este fue un discurso monocultural que no reconoció política, ni legalmente las diferencias culturales de los pueblos indígenas y afrodescendientes que han vivido en estos territorios.

La élite colombiana que lideró la revolución contra el imperio español intentó formar un Estado y una comunidad imaginada basada en sus valores culturales. El museo en Colombia surgió dentro del proceso de construcción de la nación, inmediatamente después de la independencia ganada en 1819. La idea de forjar un museo en torno a la explotación de los recursos naturales nacionales era parte de la agenda política y económica de las élites criollas de esa época. La fundación del Museo Nacional, como otros museos en América Latina, fue influenciada por la creencia de la ilustración europea en el avance de la ciencia, la tecnología y la civilización. Una comisión francesa de científicos creó el museo en Colombia para complementar una escuela de mineralogía, de esta forma el museo hacía parte de una red transatlántica de conocimiento (RodríguezPrada 2016:32).

En 1823, el nuevo gobierno republicano creó por ley el Museo de Historia Natural de Bogotá, que más tarde se convirtió en el Museo Nacional de Colombia (MNC). El museo enfatizó una retórica con dos pilares fundamentales: primero, que las riquezas en recursos naturales fueron mal administradas por los españoles en el pasado colonial y, segundo, que al país le esperaba un futuro promisorio bajo un nuevo gobierno republicano dispuesto a explotar esos recursos. El preámbulo de la Ley de 1823 indica que: “[...] al paso que han sido ignoradas en estas regiones opulentas las ciencias naturales, por una consecuencia precisa de la pésima administración de su anterior gobierno, son absolutamente necesarias para el adelantamiento de su agricultura, artes, y comercio, que son las fuentes productoras de la felicidad de los pueblos" (Decreto 28 de julio de 1823).

Esta retórica justificó la revolución e independencia y legitimó el conocimiento racional y científico a través de la colección, clasificación, exhibición y estudio de los abundantes recursos naturales de la nación procedentes de diferentes partes del país. Además, el Gobierno añadió a las colecciones objetos que fueron símbolo de la revolución contra España. Por ejemplo, en conmemoración de las victorias militares de Simón Bolívar en Junín y Ayacucho, una ley de 1825 ordenó acuñar una medalla de plata para ser preservada en el museo "con el objetivo de ser auténtica evidencia eterna de la gratitud de la nación" (Decreto 12 de febrero de 1825, artículo 3). En 1826, una ley similar ordenó que una guirnalda de oro y piedras preciosas que el revolucionario Antonio José de Sucre recibió del pueblo del Cusco se colocara "en el Museo Nacional con la distinción debida, como un monumento de gloria del ejército colombiano que dio libertad al Perú, y como un testimonio público de sus virtudes militares y cívicas" (Decreto 22 de febrero de 1826, artículo 2). La conservación de estos objetos en el museo se justificó con el propósito de recordar "a los colombianos en las generaciones venideras las glorias de su patria y las virtudes de los que han dado vida y existencia a tres naciones" (Decreto 22 de febrero de 1826, Preámbulo).

Durante el siglo XIX, la narrativa oficial del museo se puede interpretar como un intento de legitimar la independencia y utilizar las exposiciones como un poderoso agente para la construcción de una nación gobernada por el proyecto de la élite. La representación de la independencia se basó en líderes revolucionarios, parte de la élite, dirigiendo una cruzada heroica de la libertad. Los grupos subalternos, como las comunidades indígenas y negras estuvieron presentes en el museo a través de silencios y representaciones impuestas. Este es un ejemplo de comunidades como exhibición. De hecho, varias comunidades indígenas en Colombia estuvieron en contra de la revolución, apoyaron la Corona española $\mathrm{y}$, una vez que los criollos ganaron la independencia, sus miembros fueron castigados severamente, a menudo asesinados, y sus derechos sobre la tierra reconocidos por la Corona española fueron abolidos (Gutiérrez Ramos 2007). Esta resistencia nunca fue parte de las exposiciones del museo, tampoco lo fue el papel de los negros esclavos en la victoria de la independencia. Ellos lucharon con la promesa de libertad, pero las élites solo abolieron la esclavitud en 1851, décadas después de la independencia. Personas pobres reclutadas por la fuerza conformaron los ejércitos de los revolucionarios 
(Thibaud 2003), pero ellos y su realidad nunca aparecieron en las representaciones de los museos y la historia del país. Durante este periodo no hay registro de negociaciones o diálogos entre las élites que gobernaron las representaciones del museo y otras comunidades existentes en el país.

En 1880, un movimiento ultramontano conservador comenzó a tomar el poder en Colombia, el cual se consolidó con una nueva Constitución Política en 1886, impuesta por el partido Conservador, que ganó la guerra civil en 1885. En 1881 el Congreso promulgó una ley que creó un museo nacional denominado el Museo Colombiano, que mantendría las colecciones del museo creado en 1823 y cuyo objetivo fue coleccionary preservar "todos los objetos que puedan enaltecer los recuerdos históricos de la Patria y que puedan estimular y favorecer el adelanto de las ciencias" (Ley 34 de 1881, artículo 1). La referencia a "enaltecer" excluía implícitamente la creación de cualquier narrativa que colocara en entredicho o criticara el proceso de independencia y la historia oficial republicana. La ley se refirió al Museo Nacional como un "templo" donde los objetos debían ser conservados con "religioso esmero" (Ley 34 de 1881, artículo 4). La sociedad a partir del cual se desarrolló el museo era patriarcal católica, de manera que excluyó a las mujeres, los indígenas, los negros y las personas analfabetas. Las poblaciones indígenas y negras eran consideradas bárbaras, inactivas, estúpidas y provenientes de razas degeneradas. José María Samper, principal redactor de la Constitución Política de 1886, durante los debates constitucionales manifestó que los negros eran "fecundos para la procreación, perezosos, indolentes, supersticiosos en religión, de instintos groseros y sin noción alguna del derecho". De los pueblos indígenas manifestó que:

...puede decirse que esta raza degradada y deprimida se ha estancado y petrificado, pues el indio de hoy es el mismo que encontró Quesada en el tiempo de la conquista. Incapaz de civilización, no sabe leer el catecismo ni tiene conciencia de su derecho, y carece hasta del instinto más fuerte en todos los hombres, el de la curiosidad de su Dios, del cual solo sabe que existe porque el cura se lo ha dicho. Menos tiene, ni puede tener, la curiosidad de conocer las instituciones y los intereses del país, ni sus propios derechos y deberes políticos y sociales (Consejo Nacional Constituyente 1913:394).

Por el contrario, para Samper y el grupo de la élite que poseía el poder, el hombre blanco de origen español, era "altivo en el poder, aristócrata y jactancioso de su origen, caballeresco y aficionado a las cosas grandes $\mathrm{y}$ heroicas, y muy adicto a sus tradiciones" (Consejo Nacional Constituyente 1913:394). El deseo de la élite era "hispanizar" a los pueblos indígenas, erradicar las diferencias, la diversidad étnica y ocultar las realidades de la población. El ciudadano modelo era un hombre, alfabetizado, dueño de una propiedad: esta era la persona que podría ser ciudadano con derecho al voto, de acuerdo con Samper. Estos ideales fueron proyectados a través del museo.

La cultura de los pueblos indígenas se organizó en el museo como parte de un pasado remoto y, cuando estas comunidades fueron incluidas como parte del presente, fue en una narrativa de civilización y de salvación donde estas culturas eran abolidas y los pueblos indígenas asimilados. En su análisis de las colecciones del Museo Nacional entre 1880 y 1912, Amada Carolina Pérez encontró que las comunidades indígenas estaban representadas fuera del tiempo histórico, sus objetos se consideraban "curiosidades" y las comunidades negras estaban completamente ausentes de las colecciones y narrativas del museo (Pérez 2010:103). El museo conmemoró caudillos de guerra y estadistas, promovió virtudes heroicas, enalteció la producción intelectual de los líderes criollos que contribuyeron a la independencia, y dichos valores se utilizaron para educar a los nuevos ciudadanos. La narrativa del museo obedeció a la lógica de una minoría elitista, mediante la exclusión y formando una "otredad" frente a la población indígena y afrocolombiana.

La función principal del Museo Nacional fue educativa, lo cual era evidente en su ubicación dentro de la estructura administrativa del Estado. Al final del siglo XIX, el Museo Nacional quedó bajo la administración de la Universidad Nacional (Decreto 596 de 1886, artículo 54). La Ley 144 de 1948 adjudicó un monto considerable de dinero para las adquisiciones del museo, cuya administración estaría a cargo de la dirección de una junta compuesta por el Ministerio de Educación, del rector de la Universidad Nacional y del director del Museo Nacional. En 1961 el museo fue reorganizado como parte del Departamento de Comunicación Cultural del Ministerio de Educación. El objetivo "esencial" del Ministerio de Educación fue crear personas de acuerdo con "los valores de la civilización cristiana" (Decreto 1637 de 1960, artículo 1). El museo fue descrito como una entidad "destinada a coleccionar, catalogar, conservar, restaurar y dar a conocer las obras de arte y las reliquias históricas de Colombia" (Decreto 904 de 1961, artículo 1). Estos objetivos y los valores de civilización y cristiandad enmarcaron las operaciones del museo. En 1968, el museo se convirtió en parte del Instituto Colombiano de Cultura (Colcultura), dentro del Ministerio de Educación (Decreto 3154 de 1968, artículo 12).

Durante este periodo, las comunidades indígenas en Colombia carecieron de derechos y reconocimiento. Por ejemplo, hasta finales del siglo XX, mestizos y blancos participaron en una práctica genocida contra 
las comunidades sikuani o guahibo, no muy lejos de Bogotá (la capital de Colombia). Por esta época se acuño el término "guahibear", para la práctica de matar indígenas de la misma manera que cazaban animales (Molina Gómez et al. 2012). En la década de 1960, uno de estos asesinos declaró que él no sabía que matar a los indígenas estaba mal, y otro definió a los indígenas como iguales a los cristianos, pero que carecían de civilización (Castro 1986). Estos testimonios muestran como los objetivos del Ministerio de Educación asociados a la "civilización" y "cristiandad" estaban efectivamente presentes en la mentalidad de la sociedad, al mismo tiempo que la representación de inferioridad y deshumanización hacia los indígenas.

El marco constitucional y legal de carácter monocultural del siglo XIX y gran parte del siglo $\mathrm{XX}$, promovió e hizo posible que las comunidades, como exhibición fuera el único modelo adoptado por el Museo Nacional durante este periodo. En las décadas de 1970 y 1980 , un movimiento indigenista se fortaleció en el ámbito público, además un movimiento guerrillero indígena (Movimiento Armado Quintín Lame) y diferentes organizaciones indígenas y negras reivindicaron activamente sus derechos. En 1991 Colombia tuvo un cambio político: el país reemplazó su constitución de 1886 y reconoció los derechos culturales de los grupos indígenas y afrocolombianos. Este cambio constitucional creó un nuevo marco político y legal para el funcionamiento del museo.

\section{Reconocimiento constitucional del multiculturalismo}

La Constitución Política de Colombia de 1991 (artículo 7) reconoció por primera vez la diversidad étnica y cultural del país, la cual en términos numéricos de población y territorio es significativa. Los afrocolombianos representan alrededor del $20 \%$ de la población (cerca de 10 millones de personas)(AFRODES y Global Rights 2010:15). A su vez, según las estadísticas oficiales del último censo general de 2018, los pueblos indígenas (115 diferentes primeras naciones) son alrededor del $4,4 \%$ de la población de Colombia (aproximadamente 1,9 millones de personas), que viven en 710 resguardos y representan el 29,8\% del territorio de Colombia (DANE 2019). La diversidad cultural también está representada en la diversidad lingǘstica: existen 64 lenguas indígenas vivas, y dos lenguas de origen africano (creole de San Andrés y criollo Palenquero).

En 1991, además de la nueva Constitución, Colombia ratificó el convenio sobre pueblos indígenas y tribales de la Organización Internacional del Trabajo (Ley 21 de 1991). El Convenio 169 de la OIT es parte del bloque constitucional y, de acuerdo con la jurisprudencia de la Corte Constitucional de Colombia, el convenio aplica tanto para los indígenas como para las comunidades afrocolombianas (Corte Constitucional, T-955 2003). Con el Convenio de la OIT las comunidades indígenas y negras de Colombia han encontrado en el derecho a la consulta previa una herramienta legal fundamental para luchar por sus territorios y derechos culturales (Rodríguez-Garavito 2011).

Los derechos culturales específicos de las comunidades afrocolombianas e indígenas se extienden a otros derechos, como la educación, el idioma y la religión. Todos estos derechos son parte de la Constitución desde una perspectiva formal. Dentro de los resguardos, las lenguas indígenas son lenguas oficiales (Constitución Política de Colombia 1991, artículo 10). Los grupos étnicos tienen el derecho constitucional a una educación que respete y desarrolle sus identidades culturales (Constitución Política de Colombia 1991, artículo 68). Los programas y servicios educativos deben abarcar las aspiraciones económicas, sociales y culturales de las comunidades afrocolombianas (Ley 70 de 1993, artículo 35). Además, la ley para las comunidades negras estableció que el Estado debería promover la educación intercultural, incluidos los conocimientos y las contribuciones culturales de los negros a la historia del país (Ley 70 de 1993, artículo 39). Estas disposiciones organizativas intentaron reconocer y promover la autonomía e integridad cultural afrocolombiana e indígena.

Pero la realidad para las comunidades afrocolombianas e indígenas está lejos de ser consistente con la Constitución Política y el régimen jurídico. De hecho, después de la Constitución, la situación de la mayor parte de estos grupos ha empeorado. La población afrocolombiana desplazada internamente aumenta cada año. La violencia y el desplazamiento están directamente relacionadas con las políticas del Gobierno colombiano para el desarrollo y la integración del país en la economía global, promovidas por la Constitución de 1991. Por ejemplo, después de 1991, la intensiva inversión en aceite de palma, fincas ganaderas, explotación minera y megaproyectos de infraestructura en territorios de comunidades han causado una grave degradación ambiental e innumerables violaciones de derechos humanos contra los indígenas, las comunidades afrocolombianas, los campesinos y los mineros artesanales. En los últimos años los pueblos afrocolombianos e indígenas y sus territorios han sido el objetivo principal de la violencia, por ejemplo, entre enero de 2014 y agosto de 2016 estas comunidades representaron el $74 \%$ de los desplazados internos por el conflicto armado en el país (NRC-IDMC 2017:29). Un efecto de este desplazamiento es que cientos de miles de indígenas y afrocolombianos están perdiendo su forma de vida y una parte importante de su patrimonio cultural. 


\section{Museo Nacional de Colombia y el multiculturalismo}

La Constitución de 1991 impuso al Gobierno colombiano nuevas obligaciones para la gestión de las instituciones de patrimonio y memoria. En 1997, una ley estableció un nuevo marco administrativo para la política cultural del país e incorporó el Museo Nacional en el entonces recién creado Ministerio de Cultura (Ley 397 de 1997, artículo 67). En 2002, el Museo Nacional dio a conocer su plan estratégico para 2001-2010 (Ministerio de Cultura 2002); sin embargo, a pesar de destacar los compromisos legales y constitucionales frente a la cultura de los afrocolombianos e indígenas, el Museo Nacional ha sido deficiente a la hora de cambiar su representación de la nación. En 2003, el Gobierno reglamentó el museo y estableció sus nuevos objetivos y funciones. La primera y principal función del Museo Nacional es "promover y guiar el desarrollo de la museología", además, el reglamento reconoce a los museos como entidades para enriquecer la "identidad cultural nacional, regional y local" (Decreto 1746 de 2003, artículo 19-1). Solo una de las 27 funciones enumeradas en la regulación hace referencia al marco multicultural establecido por la Constitución. Se establece que el Museo Nacional debe:

...Promover la edición y publicación de catálogos científicos y la realización de exposiciones temporales e itinerantes en el Museo Nacional, basada en investigaciones que tengan interés para el país y que contribuyan al conocimiento de la diversidad cultural de la Nación (Decreto 1746 de 2003, artículos 19-12).

En la regulación no existen obligaciones o funciones explícitas del museo para promover permanentemente el patrimonio lingüístico y cultural de las comunidades negras e indígenas. Las narrativas del Museo Nacional todavía no incorporan los diversos aportes que diferentes comunidades patrimoniales han jugado en la historia de Colombia. El museo tampoco ha observado plenamente los compromisos consagrados en la nueva Constitución. Sin embargo, en respuesta a la nueva Constitución y a las crecientes demandas de activistas, el Museo Nacional ha realizado algunos intentos para modificar la tradicional narrativa adoptando un enfoque curatorial inclusivo. En 2008, la exposición temporal Velorios y santos vivos (comunidades negras, afrocolombianas, raizales y palenqueras) presentó los rituales funerarios, las prácticas y los santos de diferentes comunidades afrocolombianos y una muestra representativa de esculturas africanas de madera. Este es un ejemplo de comunidades como consultores y comunidades como participantes. En palabras de la curadora, esta exhibición "constituyó el primer esfuerzo consciente del Museo
Nacional para redimirse después de siglos de hacer invisibles a las comunidades afrocolombianas y presentar representaciones discriminatorias" (Lleras 2011:289). Esta exposición temporal, desde su concepción hasta el final, fue un trabajo conjunto por la curadora de arte e historia del Museo Nacional de Colombia, el grupo de Estudios afrocolombianos del Centro de Estudios Sociales de la Universidad Nacional de Colombia, el Ministerio de Cultura y un grupo de afrocolombianos, con la consulta y participación de representantes de organizaciones de base. Sin embargo, la toma de decisiones siempre fue realizada por el personal del museo y los antropólogos (Lleras 2011:45). El tema de los rituales funerarios se eligió con el propósito de mostrar la angustia sufrida por varias comunidades donde diferentes grupos armados han impedido que las personas realicen sus ceremonias funerarias, incluidos los entierros (Arocha 2008:21). Por medio de este proyecto, el museo buscó desempeñar un papel positivo en la reparación histórica de las comunidades afectadas por la guerra reciente en Colombia (Lleras 2012b:329). Velorios y santos vivos se presentó en diversos colegios públicos de Bogotá y como exposición itinerante en los territorios de varias comunidades negras en diversas partes del país (Lleras 2011:299). Este fue en un intento de descentralizar las prácticas del Museo Nacional, de llevar a las comunidades las contribuciones que realizaron a la exposición y mostrar lo que se presentó en Bogotá. A pesar de todas sus buenas intenciones, el proyecto fue construido y organizado por elites intelectuales y gubernamentales.

Desde el 2008, han sido escasos los proyectos inclusivos como Velorios y santos vivos en las exhibiciones del museo. La curadora que dirigió el proyecto cesó de trabajar en el museo debido a desacuerdos políticos (Lleras 2012a). Así mismo, comunidades indígenas han expresado su inconformismo al sentir encarcelados los recursos culturales que se encuentran en el museo (Londoño 2012). Todo esto ilustra que la exposición temporal fue un esfuerzo efímero, iniciado por el compromiso moral y político de algunos individuos. No puede interpretarse como el fruto de esfuerzos institucionales deliberados de la colectividad del museo, guiados por políticas y estrategias de gestión del patrimonio a largo plazo.

Como parte de un proyecto en curso de renovación de las narrativas de museo en la exposición permanente, el Museo Nacional inauguró en el 2014 una nueva sala llamada "Memoria y Nación". Esta sala está dirigida a reflejar el mandato multicultural y multiétnico de la Constitución Política de 1991, haciendo visibles las voces de grupos ignorados previamente y reescribiendo la narrativa histórica del país. Sin embargo, en esta sala la representación de las comunidades negras se muestra 
desde una perspectiva unilateral basada en las miradas de laélite tradicional (LópezDurán 2017:124). En una iniciativa más reciente, la exposición temporal Endulzar la palabra: memorias indigenas para pervivir (diciembre 2017-febrero de 2018) presentó las estrategias, procesos y luchas de ocho comunidades indígenas que enfrentan el conflicto armado interno colombiano. Su objetivo fue proporcionar una comprensión diferente del reciente conflicto interno y contribuir a un proceso nacional de construcción de paz (Sánchez 2017:12). Esta exposición fue organizada con fondos de la cooperación internacional por el Museo Nacional y el Centro Nacional para la Memoria Histórica, como parte de la creación del Museo Nacional de la Memoria.

\section{Museo Nacional de la Memoria}

El Gobierno de Colombia está creando un Museo Nacional de la Memoria destinado a forjar la memoria colectiva en relación con el periodo de violencia vivido durante las últimas décadas. Podemos rastrear el origen del Museo Nacional de la Memoria cuando, en 2003, grupos paramilitares firmaron un acuerdo de desmovilización con el gobierno de Colombia. La ley 975 de 2005, conocida como "ley de justicia y paz", creó un mecanismo de justicia transicional para los paramilitares y estableció una comisión nacional de reparación y reconciliación que creó un grupo para escribir narrativas acerca de la violencia y las violaciones a los derechos humanos (Grupo de Memoria Histórica) (Ley 975 de 2005, artículo 50). En el 2011, con la ley de reparación integral de víctimas y restitución de tierras a las personas desplazadas, ese grupo se convirtió en el Centro Nacional de Memoria Histórica (Ley 1.448 de 2011). Desde entonces, una de las funciones de este Centro es crear un Museo Nacional de la Memoria (Decreto 4.803 2011, artículo 8).

El proyecto en curso del Museo Nacional de la Memoria de Colombia intenta seguir las prácticas internacionales de los procesos de memorialización de las sociedades en posconflicto, con la dificultad que, aunque se presenta a Colombia como una sociedad en posconflicto después de un acuerdo de paz firmado por el Gobierno y la guerrilla de las FARC, la realidad muestra que los líderes indígenas y afrocolombianos son las principales víctimas de un conflicto armado en curso. El proyecto del museo ha avanzado con un marco regulatorio, el diseño arquitectónico y su ubicación. El Gobierno declaró la importancia estratégica nacional del museo y aprobó el presupuesto para su construcción desde 2017 hasta 2019 (Conpes 3909 2017).

El marco legal que ordenó la creación del Museo Nacional de la Memoria reconoció a las comunidades indígenas y afrocolombianas como sujetos colectivos de derechos de reparación debido al daño producido a la integridad cultural. Esta clase de daño comprende "el ámbito material y los sistemas simbólicos o de representaciones que configuran el ámbito intangible y espiritual [...] el patrimonio cultural; los patrones estéticos, y las estrategias y redes comunicacionales, entre otros" (Decreto Ley 4.633 de 2011, artículo 44). Esta es la primera vez que un Museo Nacional en Colombia recibe un mandato legal para incluir la participación de diferentes comunidades. De acuerdo con la regulación, los grupos étnicos, políticos "y demás formas de organización de las víctimas que han sido objeto de persecución en el marco del conflicto interno" deben participar "en la construcción y gestión del Museo de la Memoria" (Decreto 4.803 2011, artículo 13-5). Estos grupos incluyen, entre otros, sindicatos, comunidades LGBTI y defensores de los derechos humanos que han sido víctimas de masacres, secuestros, desapariciones forzadas, desplazamientos, amenazas y otras violaciones sistemáticas de derechos humanos.

Hoy, la participación de las comunidades patrimoniales en el museo es más discursiva que real. El museo estará ubicado en Bogotá, distante cultural y espacialmente de la mayoría de las comunidades. El Gobierno eligió el lugar donde se construirá el museo sin realizar una consulta efectiva con las víctimas del conflicto. El museo formará parte de un plan de desarrollo urbano llamado "eje de la paz y la memoria", que se integrará con áreas "residenciales, comerciales y de servicios que permitan recuperar la vitalidad, las condiciones de seguridad y la importancia simbólica del espacio público" (Decreto 632 de 2014, artículo 4). El diseño del edificio fue seleccionado a través de un concurso público ganado por un estudio de arquitectura español, en donde las comunidades indígenas y negras no participaron como jurados o como concursantes. Además, el Grupo de Memoria Histórica preparó los principales temas del guion museográfico (Centro Nacional de Memoria Histórica 2014:21).

Comunidades como consultores y participantes son los enfoques que el museo está tomando en su formación. El Grupo de Memoria Histórica ha llevado a cabo consultas con diferentes comunidades a nivel local, regional y nacional para la preparación de los guiones finales (Ruiz 2017). En el 2018, el museo realizó exhibiciones itinerantes para socializar su existencia, estructura y plan, con una perspectiva curatorial participativa e incluyente (Lleras et al. 2019). Sin embargo, no hay signos de compromisos políticos institucionales para empoderar a las comunidades como administradores de su patrimonio o del museo. El guion tiene que ser aprobado por la junta directiva del Centro Nacional para la Memoria Histórica, la cual incluye seis representantes de alto rango del Gobierno (cuatro ministros y dos directores de departamentos administrativos) y dos representantes de las víctimas. 
El Decreto 502 de 2017 incluyó al ministro de Defensa en el Consejo. Además, el artículo 9 de la Ley 1979 de 2019, la cual rinde homenaje y beneficios a los veteranos de la Fuerza Pública, establece que el Museo de la Memoria deberá tener un espacio físico "destinado a exponer al público las historias de vida de los veteranos de la Fuerza Pública exaltando particularmente sus acciones valerosas, su sacrificio y contribución al bienestar general". Estos puntos son muy problemáticos debido al papel que las Fuerzas Armadas de Colombia han tenido en la violación de los derechos humanos en el país (Corte Penal Internacional 2017:30). La retórica gubernamental anunció que los grupos de víctimas son el enfoque del museo y su parte central, pero en la práctica han sido excluidos de las discusiones principales sobre diseño, financiamiento y gestión (Guglielmucci 2015:24).

\section{Conclusiones}

Los valores expresados en la Constitución Política de un país y en el diseño legislativo de un museo nacional orientan su operación y relación con las comunidades. Las normas que han creado y regulado los museos nacionales muestran los cambios en sus objetivos durante sus diferentes épocas históricas, así como el papel de las comunidades en la operación del museo. En Colombia, el Museo Nacional surgió a comienzos del siglo XIX para auspiciar la llegada del conocimiento científico, especialmente de las ciencias naturales. Luego, a finales del siglo XIX, se añadió a sus objetivos el rol de la preservación y construcción de una narrativa histórica de la nación. A mediados del siglo XX, el museo se enfoca en el arte y objetos históricos, y a finales de siglo el museo adquiere un mandato profesionalizado como promotor del área de la museología en el país. Como se analizó, durante los siglos XIX y XX, las comunidades estuvieron presentes como exhibición, y a comienzos del siglo XXI se han realizado intentos para que las comunidades sean consultores. En el nuevo Museo de la Memoria Histórica, las comunidades han empezado a tener el rol de participantes; sin embargo, en ningún caso las políticas del Museo Nacional han sido formuladas teniendo en cuenta un marco que promueve la diversidad y los derechos culturales de las comunidades indígenas y afrocolombianas.

En Colombia, el museo ha contribuido a crear los estereotipos, las representaciones y los diseños institucionales que han excluido a comunidades indígenas y negras durante siglos, alimentando la violencia, la intolerancia y la indiferencia. La exclusión de las comunidades afrocolombianas e indígenas de las prácticas patrimoniales en el Museo Nacional son parte de una realidad más amplia, en la cual son política, económica y socialmente marginadas, empobrecidas, asimiladas o aniquiladas. El museo, como una institución educativa, debe ser pensado en el marco de los derechos culturales de estas comunidades.

Los museos nacionales son artefactos de la cultura occidental ajenos a las prácticas culturales de las comunidades indígenas. Sin embargo, múltiples comunidades indígenas están interesadas en participar en sus espacios, ya sea como mecanismo de descolonización o de representación. En la práctica, el Museo no ha logrado convertirse en una institución de memoria que incorpore el derecho humano al patrimonio cultural de estos grupos históricamente marginalizados. Cuando representantes de las comunidades indígenas y afrocolombianas tengan voz y poder de decisión en la operación diaria del museo y en la administración de las colecciones de museos y exposiciones (por ejemplo, al formar parte de la junta directiva del museo, como sucede en Nueva Zelanda), podrán actuar como efectivos guardianes y gestores de su patrimonio cultural, a través de la consulta, la participación y la acción directa en la gestión del patrimonio. Un marco normativo que obligue al museo a implementar el pluralismo cultural promoverá modalidades de gestión basadas en la descentralización, la colaboración y la participación. En un contexto así, un nuevo escenario de problematización para el Museo Nacional será como crear equilibrios, selección y espacios para todas las comunidades interesadas en participar.

La reciente comprensión del derecho al patrimonio como un derecho humano alienta nuevas formas de imaginar las prácticas del museo. El derecho humano al patrimonio debe sustentar el diseño, la interpretación y la implementación de la legislación y las políticas relativas a los museos nacionales. Los marcos de políticas de patrimonio cultural pluralistas y participativos guiarán los cambios en las prácticas de los museos, la construcción de procesos de promoción de múltiples voces e identidades complejas de diversas comunidades. La operación democrática de los museos nacionales ayudará a la coexistencia pacífica entre diferentes culturas en una misma jurisdicción nacional. Esto contribuirá a que las aspiraciones escritas en la Constitución Política se conviertan en realidad y como vehículo en la construcción de paz, otorgando a las comunidades sus recursos y espacios. Mediante la promoción de la pluralidad y la participación, las políticas de patrimonio pueden mediar en la deconstrucción de los marcos en los que operan las instituciones de la memoria, los cuales son un legado de los siglos XIX y XX. El Museo, como una institución con una ambición democrática, puede crear los espacios para empoderar a las comunidades a través de prácticas museísticas originales, proporcionando un mecanismo para que las comunidades participen activamente en las decisiones de colección, conservación, exhibición, programas 
educativos y en la organización administrativa del museo. Cuando esto se lleve a cabo, se podrá ver a las comunidades como gestores.
Agradeciminetos: A Iimin NAH, por las discusiones que dieron origen a este escrito. A los evaluadores, cuyas sugerencias enriquecieron esta versión final.

\section{Referencias Citadas}

Asociación Nacional de Afrocolombianos Desplazados (AFRODES) 2010. Bicentennial: Nothing to Celebrate! Report on the Human Rights of Afro-Colombian Communities in the Context of the "Celebration" of Two Hundred Years of Republican Life in Colombia. AFRODES y Global Rights, Bogotá.

Anderson, B. 2006. Imagined Communities: Reflections on the Origin and Spread of Nationalism. Verso, Nueva York.

Arocha, J. 2008. Velorios y santos vivos. En Museo Nacional de Colombia Velorios y Santos Vivos. Comunidades Negras, Afrocolombianas, Raizales y Palenqueras, coordinado por J. Arocha y C. LLeras, pp. 17-30. Museo Nacional de Colombia, Bogotá.

Aronsson, P. 2015. National Museums as Cultural Constitutions. En National Museums and Nation-Building in Europe 17502010, editado por P. Aronsson y G. Elgenius, pp. 167-199. Routledge, Nueva York.

Berger, S. 2015. National Museums in Between Nationalism, Imperialism and Regionalism, 1750-1914. En National Museums and Nation-Building in Europe 1750-2010, editado por P. Aronsson y G. Elgenius, pp. 13-32. Routledge, Nueva York.

Castro Caicedo, G. 1986. Colombia Amarga. Planeta, Bogotá.

Centro Nacional de Memoria Histórica 2014. Concurso Público de Anteproyecto Arquitectónico para el Diseño del Museo Nacional de la Memoria. Centro Nacional de Memoria Histórica, Bogotá.

Consejo Nacional Constituyente 1913. Antecedentes de la Constitución de Colombia de 1886 y Debates del Proyecto en el Consejo Nacional Constituyente. Librería Americana, Bogotá.

Departamento Administrativo Nacional de Estadística (DANE) 2019. Población Indígena de Colombia, Resultados del Censo Nacional de Población y Vivienda 2018. DANE, Bogotá.

Elgenius, G. 2015. National museums as national symbols. En National Museums and Nation-Building in Europe 1750-2010, editado por P. Aronsson y G. Elgenius, 145-166. Routledge, Nueva York.

Favier, L. 2004. La Mémoire de l'État: Histoire des Archives Nationales. Fayard, París.

Forrest, C. 2014. Immunity from seizure and suit in Australia: The Protection of Cultural Objects on Loan Act 2013. International Journal of Cultural Property 21:143-172.

Guglielmucci, A. 2015. El Museo de la Memoria y El Museo Nacional de Colombia: el arte de exponer narrativas sobre el conflicto armado interno. Mediaciones 15:10-29.

Gutiérrez Ramos, J. 2007. Los Indios de Pasto contra la República (1809-1824). Instituto Colombiano de Antropología e Historia, Bogotá.

Karp, I. 1992. Introduction. En Museums and Communities: The Politics of Public Culture, editado por I. Karp, C. Mullen y S.D. Lavine, pp. 1-17. Smithsonian Institutional Press, Washington DC.
Le Breton Poll, M. 2017. Is cultural democracy possible in a museum? International Journal of Heritage Studies 23 (9):895-898.

Lleras, C. 2011. Towards New Narratives of the Multicultural Nation: Negotiating Difference in The National Museum of Colombia. Doctoral thesis, Department of Museum Studies, University of Leicester, Leicester.

Lleras, C. 2012a. A los Museos Nacionales no les Gustan los Conflictos. Semana, 02 de marzo 2012. Disponible en: https:// www.semana.com/cultura/articulo/a-museos-nacionales-nogustan-conflictos/254324-3/.

Lleras, C. 2012b. Doors being open: Rights of Afro-descendents in the National Museum of Colombia. The Museum Journal 55 (3):327-339.

Lleras, C., S. González-Ayala, J. Botero-Mejía y C. Velandia 2019. Curatorship for meaning making: Contributions towards symbolic reparation at the Museum of Memory of Colombia. Museum Management and Curatorship 34 (6):544-561.

Londoño, W. 2012. Espíritus en prisión: Una etnografía del Museo Nacional de Colombia. Chungara Revista de Antropología Chilena 44 (4):733-745.

López Duran, G. 2017. Diversidad Cultural: Discurso Visual en el Museo Nacional de Colombia. Tesis de Maestría en Educación y Comunicación Línea de Medios, Universidad Distrital Francisco José de Caldas, Bogotá.

Martínez-Echazábal, L. 1998. Mestizaje and the discourse of national/cultural identity in LatinAmerica 1845-1959. Latin American Perspectives 25 (3):21-42.

Ministerio de Cultura. 2002. Plan Estratégico 2001-2010: Bases para el Museo Nacional del Futuro. Ministerio de Cultura, Bogotá.

Molina Gómez, N., A. Gómez López y C. Suarez Pérez 2012. Vichada: Éxodo y etnocidio indígena; el avance de la ganadería extensiva y de la colonización. Maguare 26 (1):75-121.

Mozaffari, A. 2007. Modernity and identity: The National Museum of Iran. En Museum Revolutions: How Museums Change and are Changed, editado por S.J. Knell, S. Macleod y S.E.R. Watson, pp. 87-104. Routledge, Londres.

National Museum of Australia 2015. Indigenous Cultural Rights and Engagement Principles. National Museum of Australia, Canberra.

Norwegian Refugee Council 2017. Global Report on Internal Displacement. NRC-IDMC, Geneva.

Oliver, B. 2007. From Royal to National: The Louvre Museum and the Bibliothèque Nationale. Lexington Books, Lanham.

Pérez Benavides, A. 2010. Hacer visible, hacerse visibles: la nación representada en las colecciones del Museo. Colombia 1880-1912. Memoria y Sociedad 14 (28):85-106.

Poulot, D. 2015. The changing roles of Art Museums. En National Museums and Nation-Building in Europe 1750-2010, editado por P. Aronsson y G. Elgenius, pp. 89-118. Routledge, Nueva York.

Rodríguez-Garavito, C. 2011. Ethnicity. gov: Global governance, indigenous peoples, and the right to prior consultation in Social Minefields. Indiana Journal of Global Legal Studies 18 (1):263-305. 
Rodriguez-Prada, M. 2016. The Creation of the National Museum of Colombia (1823-1830): A History of Collections, Collectors, and Museums. Museum History Journal 9 (1):29-44.

Ruiz, Y. 2017. Aseguran recursos para 'el corazón de la memoria' en Bogotá. Diario? El Espectador, 5 diciembre 2017. Disponible en: https://www.elespectador.com/noticias/nacional/aseguran-recursospara-el-corazon-de-la-memoria-en-bogota-726621/.

Sánchez, G. 2017. Presentación. En Endulzar la Palabra, Memorias Indígenas para Pervivir, editado por Centro Nacional de Memoria Histórica y Museo Nacional de Colombia, pp. 9-10. Museo Nacional de Colombia, Bogotá.

Sax, J. 1990. Heritage preservation as a public duty: The Abbé Grégoire and the origins of an idea. Michigan Law Review 88 (5):1142-1169.

Shaheed, F. 2011. Report of the Independent Expert in the Field of Cultural Rights A/HRC/17/38. United Nations Human Rights Council, Geneva.
Shiner, L. 2003. The Invention of Art: A Cultural History. University of Chicago Press, Chicago.

Steyerl, H. 2009. The institution of critique. En Art and Contemporary Critical Practice. Reinventing Institutional Critique, editado por G. Raunig y G. Ray, pp. 13-19. May Fly Books, Londres.

Taylor, C. 1994. The politics of recognition. En Multiculturalism: Examining the Politics of Recognition, editado por A. Gutmann, pp. 25-85. Princeton University Press, West Sussex.

Thibaud, C. 2003. Repúblicas en Armas: los Ejércitos Bolivarianos en la Guerra de Independencia en Colombia y Venezuela. Instituto Francés de Estudios Andinos y Editorial Planeta, Bogotá.

Wittlin, A. 1949. The Museum its History and its Tasks in Education. Routledge, Londres.

Witz, L. 2006. Transforming museums on postapartheid tourist routes. En Museum Frictions: Public Cultures/Global Transformations, editado por I. Karp, C. Kratz, L. Szwaja y T. Ybarra-Frausto, pp. 107-134. Duke University Press, Durham. 